\section{Masse, monoisotopische}

B. Güssregen

Merck KGaA, Darmstadt, Deutschland

Englischer Begriff monoisotopic mass

Beschreibung Mit monoisotopischer Masse wird die Molmasse bezeichnet, die sich aus den häufigsten Isotopen berechnen lässt. Beispielsweise für $\mathrm{CH}_{3} \mathrm{Cl}$ ergibt sich aus ${ }^{12} \mathrm{C},{ }^{1} \mathrm{H}$ und ${ }^{35} \mathrm{Cl}$ eine monoisotopische Masse (Molmasse) von $49,9923 \mathrm{~g}$.

\section{Literatur}

Murray KK et al (2005) IUPAC standard definitions of terms relating to mass spectrometry. www.msterms.com 